\title{
Effects of transversus abdominis plane block versus quadratus lumborum block on postoperative analgesia: a meta-analysis of randomized controlled trials
}

Yanqing Wang ${ }^{1 \dagger}$, Xiaojia Wang ${ }^{2 \dagger}$ and Kexian Zhang ${ }^{1 *}$

\begin{abstract}
Background: Trunk block technique has been used in postoperative analgesia for patients undergoing surgery, specifically, transversus abdominis plane block (TAPB) and quadratus lumborum block (QLB) have been proved effective. The purpose of this meta-analysis is to evaluate the effects of TAPB and QLB in postoperative analgesia.

Methods: Online databases, including MEDLINE, EMBASE, Cochrane Library (\&Trail), Web of Science, CNKI, Wanfang and QVIP were applied to collect the randomized controlled trials (RCTs) from inception to Dec. 9th, 2019. Twentytwo studies were finally included containing 777 patients in the TAPB group and 783 cases in QLB group. RCTs comparing TAPB and QLB in postoperative analgesia were included in this meta-analysis. The indicators including total analgesia consumption postoperatively, operative time, duration of anesthesia, visual analogue scale (VAS) score at $24 \mathrm{~h}$ postoperatively, duration of postoperative analgesia, the number of patients requiring analgesia postoperatively and adverse reactions were analyzed.

Results: our findings showed that morphine consumption (mg) (WMD $=3.893,95 \% \mathrm{Cl}: 2.053$ to 5.733, $P<0.001$ ), fentanyl consumption $(\mu \mathrm{g})(\mathrm{WMD}=23.815,95 \% \mathrm{Cl}: 15.521$ to $32.109, P<0.001)$, VAS score at $24 \mathrm{~h}$ postoperatively (WMD $=0.459,95 \% \mathrm{Cl}: 0.118$ to $0.801, P=0.008)$, the number of patients requiring analgesia postoperatively $(\mathrm{WMD}=$ 3.893, 95\%Cl: 2.053 to $5.733, P<0.001$ ), and the incidence of dizziness (WMD $=2.691,95 \% \mathrm{Cl}: 1.653$ to $4.382, P<$ 0.001 ) in TAPB group were higher than in QLB group.

Conclusions: QLB is superior to TAPB in reducing morphine consumption, fentanyl consumption, VAS score at $24 \mathrm{~h}$ postoperatively, the number of patients requiring analgesia postoperatively, and the incidence of dizziness.
\end{abstract}

Keywords: Transversus abdominis plane block, Quadratus lumborum block, Postoperative analgesia, Outcomes

\footnotetext{
* Correspondence: kxzhangdoctor@hotmail.com

${ }^{\dagger}$ Yanqing Wang and Xiaojia Wang contributed equally to this work.

'Department of Anesthesiology, Sichuan Cancer Hospital \& Institute, Sichuan

Cancer Center, School of Medicine, University of Electronic Science and

Technology of China, No.55, Section 4, South Renmin Road, Chengdu

610041, People's Republic of China

Full list of author information is available at the end of the article
}

(C) The Author(s). 2020 Open Access This article is licensed under a Creative Commons Attribution 4.0 International License, which permits use, sharing, adaptation, distribution and reproduction in any medium or format, as long as you give appropriate credit to the original author(s) and the source, provide a link to the Creative Commons licence, and indicate if changes were made. The images or other third party material in this article are included in the article's Creative Commons licence, unless indicated otherwise in a credit line to the material. If material is not included in the article's Creative Commons licence and your intended use is not permitted by statutory regulation or exceeds the permitted use, you will need to obtain permission directly from the copyright holder. To view a copy of this licence, visit http://creativecommons.org/licenses/by/4.0/ The Creative Commons Public Domain Dedication waiver (http://creativecommons.org/publicdomain/zero/1.0/) applies to the data made available in this article, unless otherwise stated in a credit line to the data. 


\section{Background}

Postoperative pain, including acute postoperative pain and persistent chronic postoperative pain, remains a main clinical problem. Without timely and effective treatment, acute postoperative pain can turn into persistent chronic postoperative pain [1]. Previous studies showed that $10-50 \%$ of patients undergoing surgery suffered from postoperative pain lasting more than 1 month, and $2-10 \%$ of these patients continued to experience moderate to severe chronic pain. Furthermore, inadequate postoperative analgesia continues to occur despite advances in analgesia techniques [2, 3]. Inadequate management of postoperative pain can lead to serious consequences, such as poor immediate postoperative effect, prolonged stay and/or hospital readmission, poor patient satisfaction, increased burden on patients and health systems $[3,4]$. Therefore, effective prevention and control of postoperative pain is of great significance.

Multimodal analgesia technique has been widely applied in postoperative analgesia $[3,5]$. Truncal block, including transversus abdominis plane block (TAPB), quadratus lumborum block (QLB), rectus sheath block and hernia block, plays important roles in multimodal analgesia [6, 7]. TAPB involves injecting local anesthetic into the plane between the transverse abdominis and the internal oblique, it can block the sensory nerve supply to the anterior abdominal wall by deposition of local anesthetics and has shown promising in managing postoperative pain [8-10]. QLB, similar to TAPB, was first introduced as a different form of TAPB in 2007 [11]. It is also known as an interfascial plane block because it involves injecting local anesthetics into the thoracolumbar fascia which is different from TAPB. QLB can result in a widespread sensory suppression via a wide distribution of local anesthetics, and has been increasingly used for postoperative analgesia [11-14].

In recent years, many randomized controlled trials (RCTs) have been conducted to compare the effects of TAPB and QLB in postoperative analgesia [6, 15-18]. However, the results of outcomes of postoperative analgesia were inconsistent. In the current study, we aimed to compare the efficacy of TAPB versus QLB in postoperative analgesia based on RCT articles with a metaanalysis. The indicators for this meta-analysis included total analgesia consumption postoperatively, operative time, duration of anesthesia, visual analogue scale (VAS) score at $24 \mathrm{~h}$ postoperatively, duration of postoperative analgesia, the number of patients requiring analgesia postoperatively and adverse reactions.

\section{Methods}

\section{Search strategy}

The literatures were retrieved from MEDLINE, EMBASE, Cochrane Library (\&Trail), Web of Science, CNKI,
Wanfang and QVIP the deadline for searching documents was Dec. 9th, 2019. The index words for searching literatures as follows: 'transversus abdominis' OR 'transversus abdominis plane block' OR 'transverse abdominis' OR 'transverse abdominis plane block' OR 'TAP' OR 'TAP block' OR 'TAPB' AND 'quadratus lumborum' OR 'quadratus lumborum block' OR 'quadrate lumborum' OR 'quadrate lumborum block' OR 'QL' OR 'QL block' OR 'QLB'.

\section{Inclusion and exclusion criteria}

Inclusion criteria: (1) RCTs; (2) comparison of TAPB and QLB in postoperative analgesia; (3) English and Chinese literatures; (4) outcome indicators: total analgesia consumption postoperatively, operative time, duration of anesthesia, VAS score at $24 \mathrm{~h}$ postoperatively, duration of postoperative analgesia, the number of patients requiring analgesia postoperatively and adverse reactions.

Exclusion criteria: (1) reviews, meta-analyses, conference articles and letters; (2) animal experiments; (3) repetitive studies; (4) articles that cannot extract the valid data.

\section{Methodological quality appraisal}

The studies were screened independently by two researchers Y Wang and X Wang. In the event of disagreements, a third party (K Zhang) would participate in the discussion. The modified Jadad scale (Table 1) was applied to evaluate the quality of literatures. The scale was

Table 1 The modified Jaded Scale

\begin{tabular}{|c|c|c|}
\hline Classification & Score & Description \\
\hline \multicolumn{3}{|l|}{ Randomization } \\
\hline Inappropriate & 0 & Semi-randomized or quasi-randomized trials \\
\hline Unclear & 1 & $\begin{array}{l}\text { Randomized trials without describing methods } \\
\text { for generating random sequences }\end{array}$ \\
\hline Appropriate & 2 & $\begin{array}{l}\text { Random sequences produced by a computer } \\
\text { or a random number table }\end{array}$ \\
\hline \multicolumn{3}{|c|}{ Allocation concealment } \\
\hline Inappropriate & 0 & Regular grouping \\
\hline Unclear & 1 & $\begin{array}{l}\text { Only use of a random number table or other } \\
\text { random assignment scheme }\end{array}$ \\
\hline Appropriate & 2 & $\begin{array}{l}\text { A method for assigning sequences without } \\
\text { prediction }\end{array}$ \\
\hline \multicolumn{3}{|l|}{ Blinding } \\
\hline Inappropriate & 0 & $\begin{array}{l}\text { Use of double blindness without an } \\
\text { appropriate method }\end{array}$ \\
\hline Unclear & 1 & Only mention of double blindness \\
\hline Appropriate & 2 & $\begin{array}{l}\text { A description of the specific and appropriate } \\
\text { method of double blindness }\end{array}$ \\
\hline \multicolumn{3}{|c|}{ Withdrawals or dropouts } \\
\hline No & 0 & No description of withdrawal or dropouts \\
\hline Yes & 1 & A description of withdrawal or dropouts \\
\hline
\end{tabular}


Table 2 Characteristics of studies included in meta-analysis

\begin{tabular}{|c|c|c|c|c|c|c|c|c|c|c|}
\hline Author & Year & Country & Score & Treatment & TAPB_n (M/F) & TAPB_age" (years) & QLB_n (M/F) & QLB_age ${ }^{\#}$ (years) & Quality & Outcomes \\
\hline Baytar & 2019 & Turkey & 4 & TAPB vs QLB & $53(11 / 42)$ & $48.12 \pm 12.42$ & $54(15 / 39)$ & $46.42 \pm 16.57$ & $\mathrm{HQ}$ & $\mathrm{bfg}$ \\
\hline Yousef & 2018 & Egypt & 5 & TAPB vs QLB & $30(0 / 30)$ & $50.70 \pm 6.8$ & $30(0 / 30)$ & $56.5 \pm 6.97$ & $\mathrm{HQ}$ & $a b c d e f$ \\
\hline Kumar & 2018 & India & 4 & TAPB vs QLB & $35(15 / 20)$ & $38.34 \pm 11.59$ & $35(15 / 19)$ & $39.20 \pm 11.64$ & $\mathrm{HQ}$ & $a b d f$ \\
\hline Öksüz & 2017 & Turkey & 3 & TAPB vs QLB & $25(21 / 4)$ & $3.02 \pm 1.82$ & $25(21 / 4)$ & $3.13 \pm 0.20$ & LQ & ef \\
\hline Blanco & 2016 & Arab & 3 & TAPB vs QLB & $38(0 / 38)$ & NA & $38(0 / 38)$ & NA & LQ & a \\
\hline Verma & 2019 & India & 6 & TAPB vs QLB & $30(0 / 30)$ & $28 \pm 3$ & $30(0 / 30)$ & $30 \pm 3$ & $\mathrm{HQ}$ & $b d f$ \\
\hline Ipek & 2019 & Turkey & 3 & TAPB vs QLB & $29(19 / 10)$ & $4.16 \pm 2.55$ & $35(28 / 7)$ & $3.89 \pm 3.26$ & LQ & efg \\
\hline Shan & 2019 & China & 3 & TAPB vs QLB & $30(0 / 30)$ & $30 \pm 3$ & $30(0 / 30)$ & $29 \pm 6$ & LQ & $c f$ \\
\hline Deng & 2019 & China & 6 & TAPB vs QLB & $34(12 / 22)$ & $53.5 \pm 10.6$ & $34(14 / 20)$ & $51.1 \pm 13.8$ & $\mathrm{HQ}$ & $b c f$ \\
\hline $\mathrm{Fu}$ & 2019 & China & 4 & TAPB vs QLB & $30(\mathrm{NA})$ & $71.8 \pm 5.8$ & $30(\mathrm{NA})$ & $72.2 \pm 6.9$ & $\mathrm{HQ}$ & $b f$ \\
\hline Han & 2017 & China & 4 & TAPB vs QLB & $38(24 / 14)$ & $27.8 \pm 3.9$ & $39(20 / 19)$ & $26.3 \pm 3.2$ & $\mathrm{HQ}$ & $b c f$ \\
\hline $\mathrm{He}$ & 2018 & China & 2 & TAPB vs QLB & $36(20 / 16)$ & $67.3 \pm 2.3$ & $36(19 / 17)$ & $67.7 \pm 2.1$ & LQ & ef \\
\hline Li G & 2018 & China & 5 & TAPB vs QLB & $40(0 / 40)$ & $31 \pm 4$ & $40(0 / 40)$ & $30 \pm 5$ & $\mathrm{HQ}$ & $b c f$ \\
\hline Li N & 2019 & China & 3 & TAPB vs QLB & $30(0 / 30)$ & $42.10 \pm 5.26$ & $30(0 / 30)$ & $41.07 \pm 4.75$ & LQ & bef \\
\hline $\mathrm{Ma}$ & 2019 & China & 3 & TAPB vs QLB & $30(17 / 13)$ & $55.2 \pm 4.4$ & $30(16 / 14)$ & $53.1 \pm 4.6$ & LQ & e \\
\hline Ren & 2018 & China & 3 & TAPB vs QLB & $82(44 / 38)$ & $45.7 \pm 15.2$ & $78(40 / 38)$ & $46.3 \pm 15.1$ & LQ & $b c$ \\
\hline Xia & 2018 & China & 4 & TAPB vs QLB & $30(15 / 15)$ & $48 \pm 8$ & $30(12 / 18)$ & $46 \pm 11$ & $\mathrm{HQ}$ & f \\
\hline Yang & 2019 & China & 3 & TAPB vs QLB & $30(0 / 30)$ & NA & $30(0 / 30)$ & NA & LQ & $a b$ \\
\hline Yang & 2019 & China & 5 & TAPB vs QLB & $30(0 / 30)$ & $38.5 \pm 14.8$ & $30(0 / 30)$ & $43.9 \pm 15.04$ & $\mathrm{HQ}$ & bcef \\
\hline Ye & 2019 & China & 4 & TAPB vs QLB & $28(12 / 16)$ & $48.9 \pm 2.1$ & $30(14 / 16)$ & $50.3 \pm 2.8$ & $\mathrm{HQ}$ & $c f$ \\
\hline Zhu & 2019 & China & 3 & TAPB vs QLB & $39(20 / 19)$ & $68.8 \pm 3.4$ & $39(18 / 21)$ & $69.1 \pm 3.2$ & LQ & ef \\
\hline Zhu & 2018 & China & 3 & TAPB vs QLB & $30(0 / 30)$ & $52 \pm 6$ & $30(0 / 30)$ & $51 \pm 7$ & LQ & bef \\
\hline
\end{tabular}

\#: mean \pm standard deviation

$T A P B$ transversus abdominis plane block, $Q L B$ quadratus lumborum block, VAS visual analog scale, $H Q$ high-quality, $L Q$ low-quality, NA unavailable

a: morphine consumption; b: VAS score at $24 \mathrm{~h}$ postoperatively; c: fentanyl consumption; $d$ : duration of postoperative analgesia; e: the number of patients requiring analgesia postoperatively; f: operative time; g: duration of anesthesia

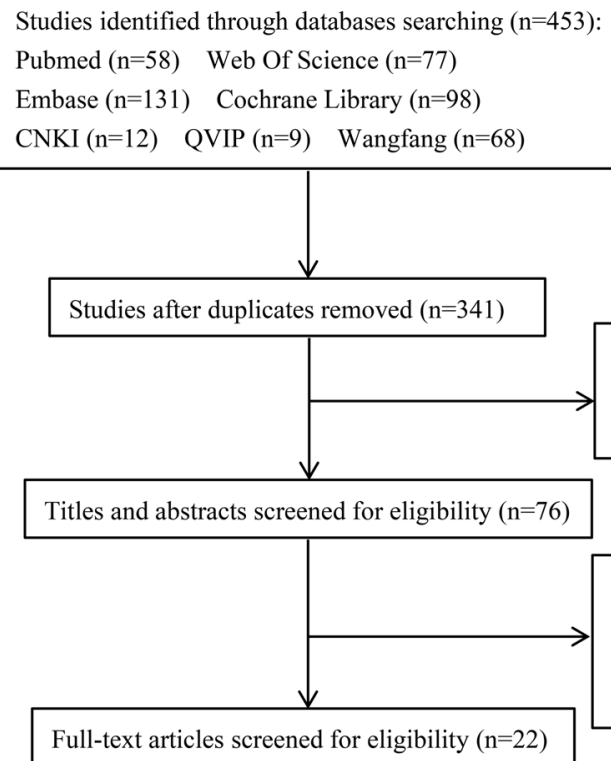

Full-text articles screened for eligibility $(\mathrm{n}=22)$

Fig. 1 Flow chart of the review process 
divided into 7 points, 1-3 were defined as low quality, and 4-7 were defined as high quality.

\section{Statistical analysis}

Heterogeneity test was conducted for each indicator and measured by statistics of $\mathrm{I}^{2}$, with $\mathrm{I}^{2}>50 \%$ indicating significant heterogeneity. If $\mathrm{I}^{2}>50 \%$, a random effects model was used; if $\mathrm{I}^{2}<50 \%$, the fixed effects model was applied, and the heterogeneity was assessed. The software Stata 15.0 (Stata Corporation, College Station, TX, USA) was used for statistical analysis, effect index relative risk (RR) was used for enumeration data and weighted mean difference (WMD) for measurement data. $P<0.05$ was considered statistically significant.

\section{Results}

\section{Included studies}

According to the search strategy, literature searches via the databases identified 453 articles. Following removing duplicates, screening titles or abstracts, and after assessing the full texts of relevant studies, 22 articles [6, 15-35] were finally included containing 777 patients in the TAPB group and 783 cases in QLB group (Table 2 and Fig. 1).

\section{Overall meta-analysis}

As shown in Table 3, our findings showed that morphine consumption (mg) (WMD $=3.893$, 95\%CI: 2.053 to 5.733 , $P<0.001$ ), fentanyl consumption $(\mu \mathrm{g}) \quad(\mathrm{WMD}=23.815$, 95\%CI: 15.521 to $32.109, P<0.001)$, VAS score at $24 \mathrm{~h}$ postoperatively (WMD $=0.459,95 \% \mathrm{CI}: 0.118$ to 0.801 , $P=0.008)$, the number of patients requiring analgesia postoperatively (WMD $=3.893,95 \% \mathrm{CI}$ : 2.053 to $5.733, P<$ $0.001)$, and the incidence of dizziness $(\mathrm{RR}=2.691,95 \% \mathrm{CI}$ : 1.653 to $4.382, P<0.001)$ in TAPB group were higher than in QLB group. No significant differences were observed between the two groups regarding the operative time (min) $(P=0.573)$, duration of anesthesia $(\min )(P=0.733)$, duration of postoperative analgesia $(\mathrm{h})(P=0.258)$, and nausea and vomiting $(P=0.141)$.

\section{Total analgesia consumption postoperatively}

Total analgesia consumption postoperatively $(\mathrm{mg})$ as an outcome was reported containing 4 studies $(n=266)$ on morphine consumption $(\mathrm{mg})$ and 8 articles $(n=623)$ on fentanyl consumption $(\mu \mathrm{g})$. Patients in TAPB group consumed more morphine than QLB group (WMD $=3.893$, 95\%CI: 2.053 to 5.733; $P<0.001$ ) (Table 3 and Fig. 2 a). Heterogeneity among the included studies was statistically significant $\left(\mathrm{I}^{2}=72.7 \%\right)$. Subgroup analysis was performed to identify sources of heterogeneity. According to operation types and literature quality, there were significant differences in abdominal surgery $(\mathrm{WMD}=2.400,95 \% \mathrm{CI}$ : 1.825 to $2.975, P<0.001$ ), pelvic surgery (WMD: 4.731 ,
Table 3 Overall results of the meta-analysis

\begin{tabular}{|c|c|c|c|}
\hline Outcomes & WMD/RR (95\%Cl) & $P$ & $1^{2}$ \\
\hline \multicolumn{4}{|c|}{ Morphine consumption (mg) } \\
\hline Overall & $3.893(2.053,5.733)$ & $<0.001$ & 72.7 \\
\hline \multicolumn{4}{|l|}{ Operation types } \\
\hline Abdominal surgery & $2.400(1.825,2.975)$ & $<0.001$ & NA \\
\hline Pelvic surgery & $4.731(2.634,6.829)$ & $<0.001$ & 44.5 \\
\hline \multicolumn{4}{|l|}{ Quality } \\
\hline High-quality & $3.205(1.283,5.127)$ & 0.001 & 76.2 \\
\hline Low-quality & $6.443(0.098,12.788)$ & 0.047 & 72.2 \\
\hline \multicolumn{4}{|l|}{ Fentanyl consumption $(\mu \mathrm{g})$} \\
\hline Overall & $23.815(15.521,32.109)$ & $<0.001$ & 96.0 \\
\hline \multicolumn{4}{|l|}{ Operation types } \\
\hline Abdominal surgery & $14.077(7.412,20.742)$ & $<0.001$ & 92.3 \\
\hline Pelvic surgery & $34.808(14.079,55.537)$ & 0.001 & 96.5 \\
\hline \multicolumn{4}{|l|}{ Quality } \\
\hline High-quality & $26.576(13.594,39.558)$ & $<0.001$ & 96.9 \\
\hline Low-quality & $16.264(7.527,25.000)$ & $<0.001$ & 73.3 \\
\hline \multicolumn{4}{|l|}{ Operative time } \\
\hline Overall & $0.324(-0.805,1.454)$ & 0.573 & 0.0 \\
\hline \multicolumn{4}{|c|}{ Duration of anesthesia (min) } \\
\hline Overall & $-2.139(-14.423,10.146)$ & 0.733 & 80.8 \\
\hline \multicolumn{4}{|c|}{ VAS score at $24 \mathrm{~h}$ postoperatively } \\
\hline Overall & $0.459(0.118,0.801)$ & 0.008 & 94.8 \\
\hline \multicolumn{4}{|l|}{ Operation types } \\
\hline Abdominal surgery & $0.224(-0.033,0.480)$ & 0.088 & 80.1 \\
\hline Pelvic surgery & $0.671(0.103,1.240)$ & 0.021 & 95.4 \\
\hline \multicolumn{4}{|l|}{ Quality } \\
\hline High-quality & $0.576(0.048,1.104)$ & 0.032 & 96.3 \\
\hline Low-quality & $0.218(-0.019,0.455)$ & 0.071 & 66.1 \\
\hline \multicolumn{4}{|c|}{ Duration of postoperative analgesia } \\
\hline Overall & $-21.882(-59.774,16.010)$ & 0.258 & 100.0 \\
\hline \multicolumn{4}{|l|}{ Operation types } \\
\hline Abdominal surgery & $-3.400(-4.038,-2.762)$ & $<0.001$ & NA \\
\hline Pelvic surgery & $-31.125(-78.851,16.600)$ & 0.201 & 100.0 \\
\hline \multicolumn{4}{|c|}{ Number of patients requiring analgesia postoperatively } \\
\hline Overall & $2.618(2.040,3.361)$ & $<0.001$ & 13.2 \\
\hline \multicolumn{4}{|l|}{ Adverse reactions } \\
\hline \multicolumn{4}{|l|}{ Dizziness } \\
\hline Overall & $2.691(1.653,4.382)$ & $<0.001$ & 0.0 \\
\hline \multicolumn{4}{|l|}{ Nausea and vomiting } \\
\hline Overall & $1.918(0.805,4.571)$ & 0.141 & 50.9 \\
\hline \multicolumn{4}{|l|}{ Quality } \\
\hline High-quality & $4.100(1.932,8.699)$ & $<0.001$ & 0.0 \\
\hline Low-quality & $0.417(0.054,3.239)$ & 0.403 & 70.9 \\
\hline
\end{tabular}

$C /$ confidence interval, $R R$, risk ratio, $W M D$ weighted mean difference, VAS visual analog scal, $N A$ unavailable 

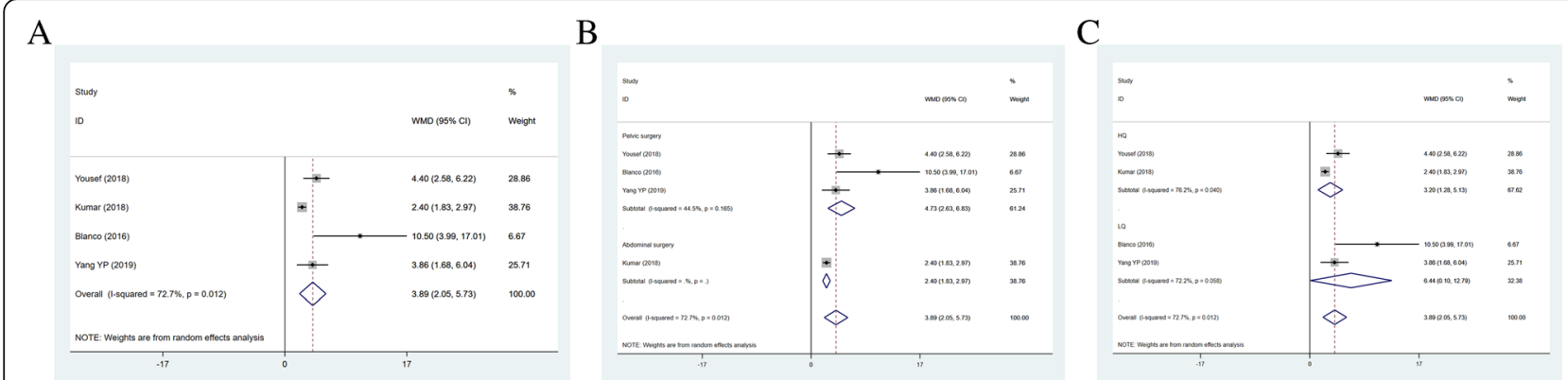

Fig. 2 Forest plot for morphine consumption (a), operation types (b) and literature quality (c)

95\%CI: 2.634 to $6.829, P<0.001$ ), high-quality (WMD = 3.205, 95\%CI: 1.283 to $5.127, P=0.001$ ) and low-quality (WMD $=6.443,95 \% \mathrm{CI}: 0.098$ to $12.788, P=0.047$ ) between the two groups (Fig. $2 \mathrm{~b}$ and $\mathrm{c}$ ). The fentanyl consumption in TAPB group was higher than that in QLB group (WMD $=23.815,95 \% \mathrm{CI}: 15.521$ to $32.109, P<$ 0.001) (Table 3 and Fig. 3a). We also found statistical differences in abdominal surgery (WMD $=14.077$, 95\%CI: 7.412 to $20.742, P<0.001$ ), pelvic surgery (WMD: 34.808 , $95 \% \mathrm{CI}$ : 14.079 to $55.537, P<0.001$ ), high-quality (WMD = 26.576, 95\%CI: 13.594 to $39.558, P<0.001$ ) and lowquality (WMD $=16.264,95 \% \mathrm{CI}: 7.527$ to $25.000, P<$ 0.001 ) between the two groups (Fig. $3 \mathrm{~b}$ and c).

\section{Operative time}

Eighteen articles $(n=1204)$ on operative time $(\mathrm{min})$ were included containing 597 patients in TAPB group and 607 patients in QLB group. The operative time in TAPB group was similar to QLB group, with no significant differences (WMD $=0.324,95 \% \mathrm{CI}:-0.805$ to $1.454, P=0.573$ ).

\section{Duration of anesthesia}

The data of duration of anesthesia (min) as a clinical outcome was extracted from 2 articles including 171 cases. Duration of anesthesia in TAPB group was near to QLB group, with no significant differences (WMD = 2.139, 95\%CI: -14.423 to10.146, $P=0.733$ ).

\section{VAS score at $\mathbf{2 4} \mathrm{h}$ postoperatively}

Thirteen studies, including 982 patients, reported VAS score at $24 \mathrm{~h}$ postoperatively for pain as an outcome $\left(\mathrm{I}^{2}=\right.$ $94.8 \%)$. The VAS score at $24 \mathrm{~h}$ postoperatively in TAPB group was higher than that in QLB group (WMD $=0.459$, 95\% CI: 0.118 to $0.801 ; P=0.008$ ) (Fig. $4 a$ ). The results of subgroup analysis showed statistical differences in pelvic surgery (WMD $=0.671,95 \% \mathrm{CI}: 0.103$ to $1.240, P=0.021$ ) and high-quality (WMD $=0.576,95 \% \mathrm{CI}: 13.594$ to 39.558 , $P<0.001$ ) (Fig. 4b and c).

\section{Duration of postoperative analgesia}

The duration of postoperative analgesia (h) was reported as an outcome in 3 studies $(n=190)\left(\mathrm{I}^{2}=100.00 \%\right)$. Duration of postoperative analgesia in TAPB group was shorter than QLB group (WMD $=-21.882$, 95\% CI: 59.774 to $16.010, P=0.258$ ) (Fig. 5a). The findings also showed differences in abdominal surgery (WMD = 3.400, 95\% CI: -4.038 to $-2.762, P<0.001$ ) (Fig. $5 \mathrm{~b}$ ).

\section{The number of patients requiring analgesia postoperatively}

Nine studies (564 patients) on the number of patients requiring analgesia postoperatively were analyzed $\left(\mathrm{I}^{2}=13.2 \%\right)$. The results founded that the number of patients requiring analgesia after surgery in TAPB group were higher than QLB group ( $\mathrm{RR}=2.618,95 \% \mathrm{CI}: 2.040$ to $3.361, P<0.001)$.

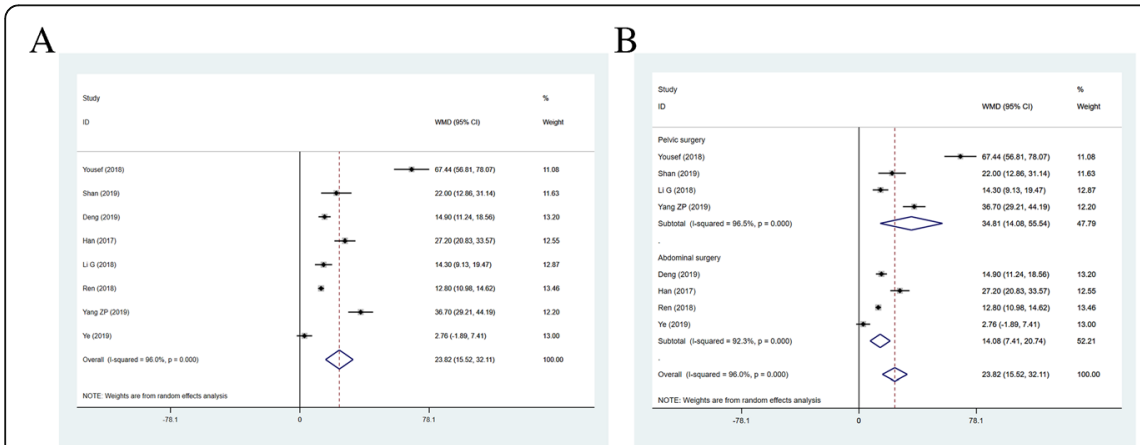

C

Fig. 3 Forest plot for of fentanyl consumption (a), operation types (b) and literature quality (c)

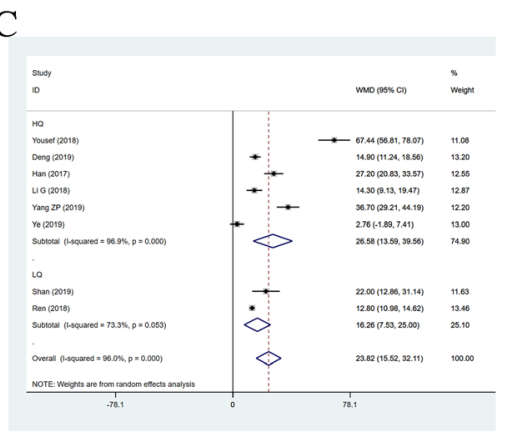


A

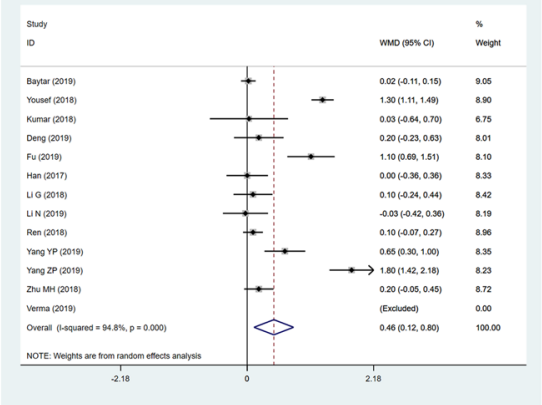

B

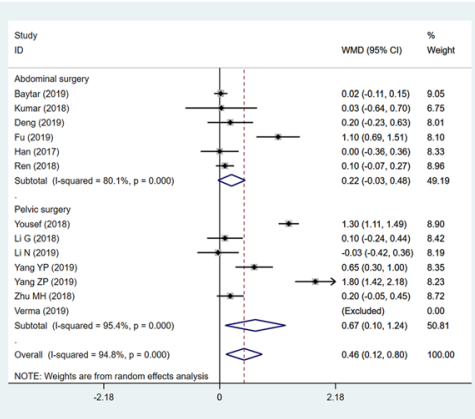

C

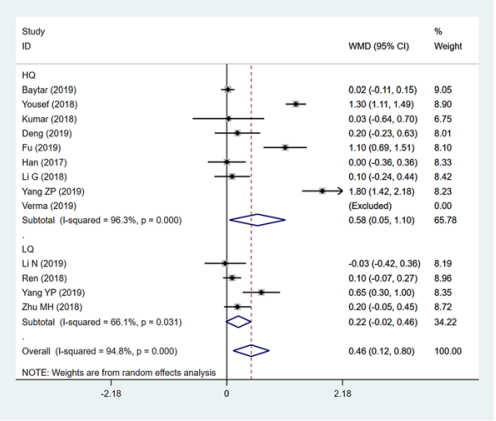

Fig. 4 Forest plot for VAS score at $24 \mathrm{~h}$ postoperatively (a), operation types (b) and literature quality (c)

\section{Adverse reactions}

The incidence of dizziness in TAPB group from 5 articles was $(n=361)$ higher than that in QLB group $\left(\mathrm{I}^{2}=0.0 \%\right.$, $\mathrm{RR}=2.691,95 \%$ CI: 1.653 to $4.382, P<0.001$ ) (Fig. 6). 8 studies $(n=535)$ on the incidence of nausea and vomiting were no differences between the two groups $\left(\mathrm{I}^{2}=50.9 \%\right.$, $\mathrm{RR}=1.918,95 \%$ CI: 0.805 to $4.571, P=0.141$ ).

\section{Publication bias}

Publication bias was performed using Begg' test. There were no distinct publication bias in morphine consumption $(\mathrm{Z}=1.36, P=0.174)$, operative time $(\mathrm{Z}=1.17, P=0.240)$, duration of anesthesia $(\mathrm{Z}=1.00, P=0.317)$, VAS score at 24 h postoperatively $(\mathrm{Z}=1.10, P=0.273)$, duration of postoperative analgesia $(Z=-1.00, P=0.317)$, the number of patients requiring analgesia postoperatively $(Z=-0.42, P=$ $0.677)$, the incidence of dizziness $(\mathrm{Z}=0.49, P=0.624)$, and nausea and vomiting $(Z=-0.12, P=1.000)$, except fentanyl consumption $(\mathrm{Z}=2.23, P=0.026)$.

\section{Discussion}

Twenty-two studies $[6,15-20]$ on effects of TAPB vs. QLB in postoperative analgesia were included in this meta-analysis. Overall results showed that QLB showed more effective analgesia than TAPB in regards to morphine consumption, fentanyl consumption, VAS score at $24 \mathrm{~h}$ postoperatively, the number of patients requiring analgesia postoperatively, and the incidence of dizziness.

Pain was regarded as the fifth vital sign by the joint commission on accreditation of medical institutions (JCAHO) in 2000, ignoring pain management equals disrespecting human rights [36]. Postoperative pain is a major concern for patients and clinicians. Inadequate management of postoperative pain remains a common clinical problem worldwide [3, 4, 37]. TAPB has been described as a successful adjunct procedure for postoperative analgesia, however with some complications: failure of block, abdominal organ injury, nerve injury, vascular injury and so on [38-40]. Fortunately, the application of ultrasound can display injection point, the tap plane and the needle. With the guidance of ultrasound, the accuracy of puncture is improved, and the related complications are reduced $[13,41]$. However, TAPB only blocks the anterolateral skin, muscles and parietal peritoneal sensory nerve fibers of the abdominal wall, and has no inhibitory effect on visceral pain [42]. QLB, as an

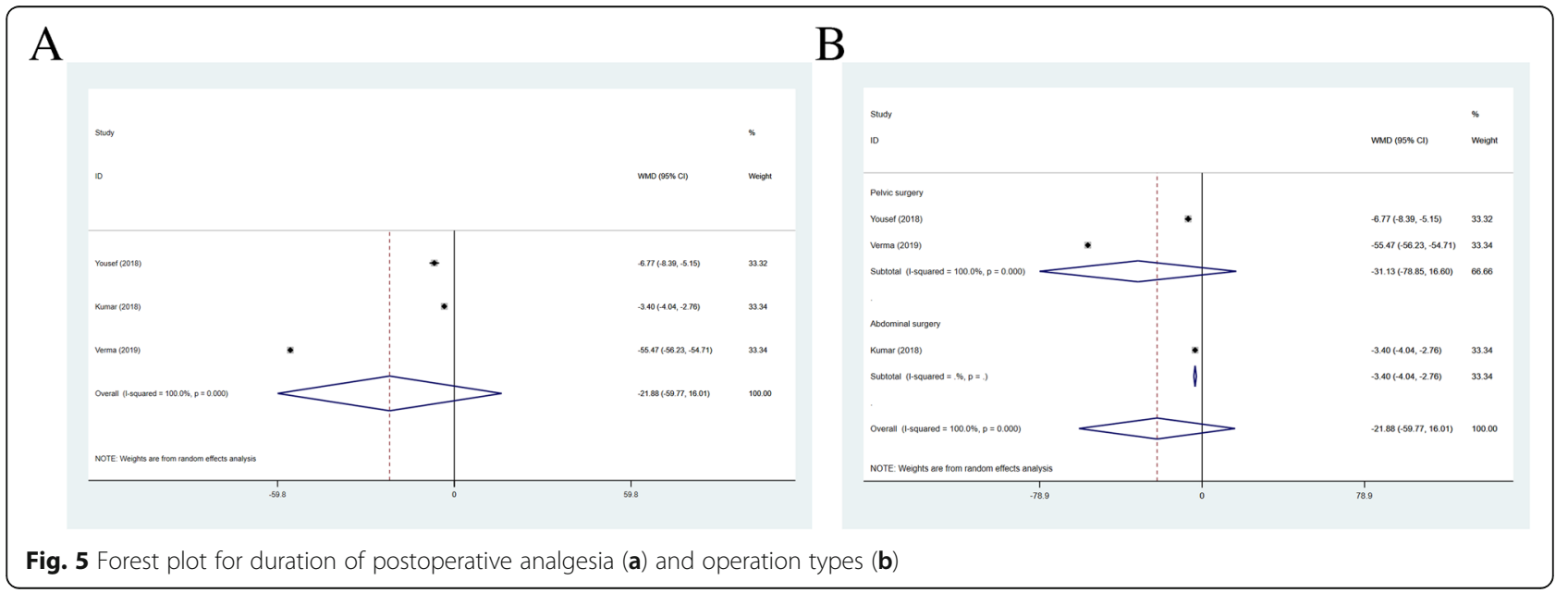




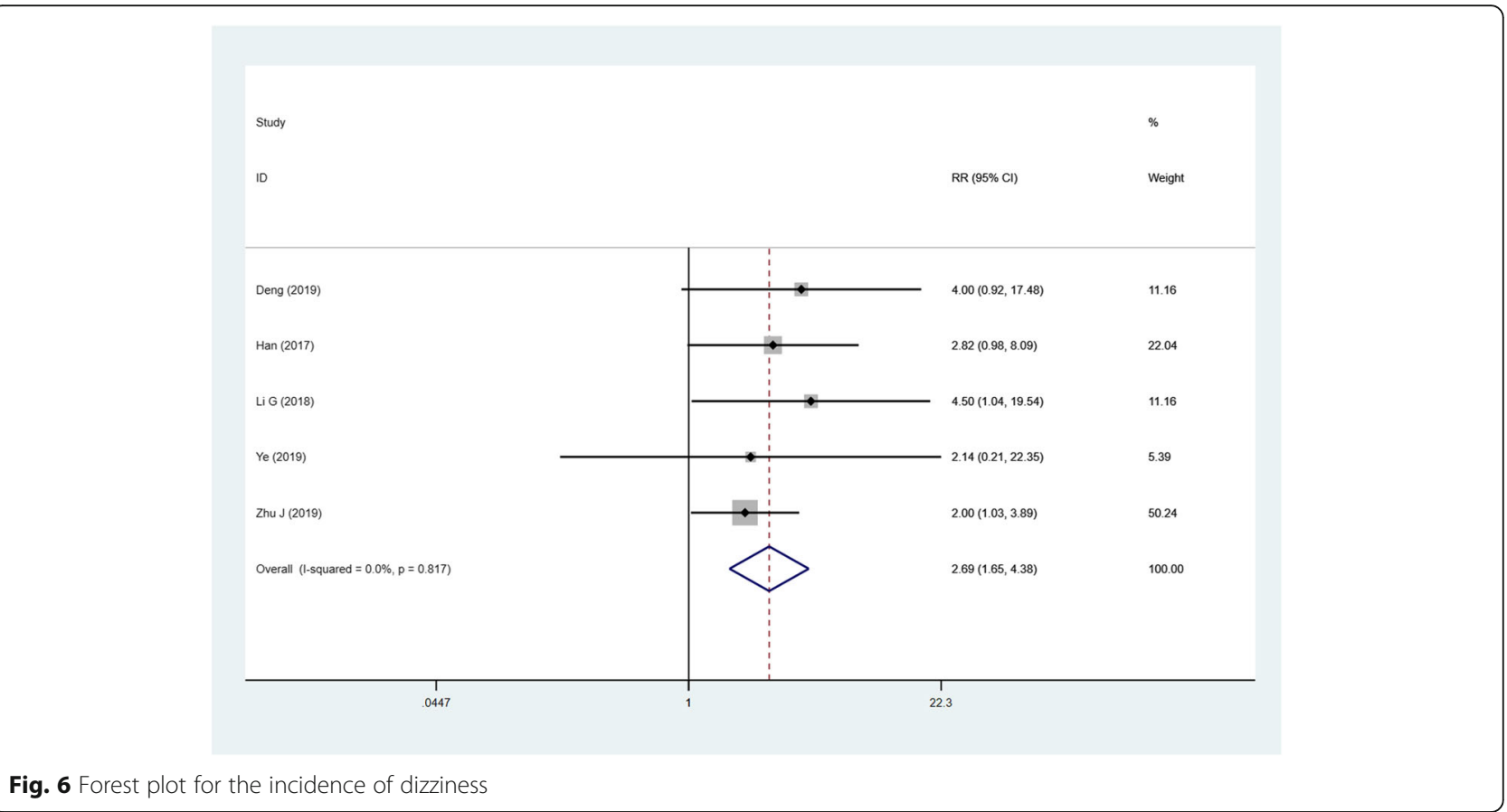

effective and reliable option for relieving postoperative pain, is performed exclusively under the guidance of ultrasound, and the passage of the needle and the site of the local anesthetic application are far from the abdominal organs, great vessels and peritoneal cavity [43-47]. QLB can block the sympathetic nerves distributed between the thoracolumbar fascias. Some scholars suggested that QLB may alleviate the visceral pain to a certain extent [48]. Compared with TAPB, the drug diffusion range of QLB drugs was relatively wide, even reaching the paravertebral space of chests [49].

In this meta-analysis, VAS score at $24 \mathrm{~h}$ postoperatively of TAPB group was higher than that of QLB group, which may cause high consumption of analgesics. We also found that morphine and fentanyl consumption postoperatively in TAPB group were higher than QLB group. Similarly, a previous study showed that QLB type 1 significantly reduced morphine consumption up to postoperative $48 \mathrm{~h}$ [50]. Salama et al. found that QLB performed after cesarean section provided an ideal effect in reducing total postoperative morphine consumption [44]. The reason why the patients in TAPB group consumed more morphine than QLB group may be that TAPB only provides effective somatic analgesia, however poor effect in visceral analgesia [47]. Yousef reported that patients undergoing hysterectomy bilateral QLB provided more effective intraoperative and postoperative analgesia with less intraoperative fentanyl consumption and less postoperative morphine consumption compared with bilateral TAPB [18]. As we all know, morphine and fentanyl are common analgesic drugs for pain, and excessive use may cause several adverse reactions. Herein, it is significant for postoperative analgesia to explore an adjunct procedure that can reduce analgesia consumption.

The number of patients requiring analgesia postoperatively in QLB group was less than TAPB group. Zhu et al. [51] have studied the rate at patients who receive QLB requested analgesia postoperatively. They performed ultrasound-guided subcostal approach to QLB in an ipsilateral parasagittal oblique plane at the L1-L2 level on patients who underwent laparoscopic nephrectomy, and they reported that QLB was related with reducing rate of patients requiring rescue analgesia postoperatively. There were no significant differences in the operative time, duration of anesthesia, duration of postoperative analgesia, and nausea and vomiting between the two groups. The reasons may be less number of articles and small sample size included in this study. More high-quality studies with large samples are needed to further verify these results.

Because of representing the high level of evidences, the meta-analysis of RCTs can help patients, doctors and policy-makers to make decisions [52]. This metaanalysis was conducted to compare the effect of TAPB and QLB on postoperative analgesia based on RCT studies. However, several limitations of this study should be noted. First, heterogeneity existed in some measurements, and subgroup analyses failed to change the heterogeneity. Furthermore, there was a publication bias in fentanyl consumption, which may be attributed to the fact that the positive results were easy to publish, and only one English article and 2 low-quality studies were included in this meta-analysis. These factors mentioned 
above may affect our results. Therefore, the current results should be interpreted with caution.

\section{Conclusions}

In summary, compared with TAPB, QLB provided effective intraoperative and postoperative analgesia with less morphine consumption, less fentanyl consumption, lower VAS score at $24 \mathrm{~h}$ postoperatively, decreased number of patients requiring analgesia postoperatively, and reduced incidence of dizziness. In addition, QLB is comparable with TAPB as regards to operative time, duration of anesthesia, and the incidence of nausea and vomiting. More researches with well-designed and adequate sample size are required to confirm these findings.

\section{Abbreviations}

TAPB: Transversus abdominis plane block; QLB: Quadratus lumborum block; RCTs: Randomized controlled trials; VAS: Visual analogue scale; RR: Relative risk; WMD: Weighted mean difference; JCAHO: Joint commission on accreditation of medical institutions

\section{Acknowledgements}

Not applicable.

\section{Authors' contributions}

All authors conceived and designed the study. YQW and XJW participated in manuscript writing, data collection and data analysis. KYZ critically reviewed and edited the manuscript. All authors read and approved the final manuscript.

\section{Funding}

No funding

\section{Availability of data and materials}

All data generated or analyzed during this study are included in this published article.

\section{Ethics approval and consent to participate}

Not applicable.

\section{Consent for publication}

Not applicable.

\section{Competing interests}

The authors declare that they have no competing interests.

\section{Author details}

${ }^{1}$ Department of Anesthesiology, Sichuan Cancer Hospital \& Institute, Sichuan Cancer Center, School of Medicine, University of Electronic Science and Technology of China, No.55, Section 4, South Renmin Road, Chengdu 610041, People's Republic of China. ${ }^{2}$ Department of Pain management, West China Hospital, Sichuan University, Chengdu 610041, People's Republic of China

Received: 31 October 2019 Accepted: 1 April 2020

Published online: 04 May 2020

\section{References}

1. Lovich-Sapola J, Smith CE, Brandt CP. Postoperative pain control. Surg Clin N Am. 2015;95(2):301-18

2. Grosu I, de Kock M. New concepts in acute pain management: strategies to prevent chronic postsurgical pain, opioid-induced hyperalgesia, and outcome measures. Anesthesiol Clin. 2011;29(2):311-27.

3. Rawal N. Current issues in postoperative pain management. Eur Anaesthesiol. 2016;33(3):160-71.
4. Wu MS, Chen KH, Chen IF, Huang SK, Tzeng PC, Yeh ML, Lee FP, Lin JG, Chen $\mathrm{C}$. The efficacy of acupuncture in post-operative pain management: a aystematic review and meta-analysis. PLoS One. 2016;11(3):e0150367.

5. Chandon M, Bonnet A, Burg Y, Barnichon C, DesMesnards-Smaja V, Sitbon B, Foiret C, Dreyfus JF, Rahmani J, Laloe PA, et al. Ultrasound-guided transversus abdominis plane block versus continuous wound infusion for post-caesarean analgesia: a randomized trial. PLoS One. 2014;9(8):e103971.

6. Oksuz G, Bilal B, Gurkan Y, Urfalioglu A, Arslan M, Gisi G, Oksuz H. Quadratus lumborum block versus transversus abdominis plane block in children undergoing low abdominal surgery: a randomized controlled trial. Reg Anesth Pain Med. 2017:42(5):674-9.

7. Chakraborty A, Khemka R, Datta T. Ultrasound-guided truncal blocks: a new frontier in regional anaesthesia. Indian J anaesth. 2016;60(10):703-11.

8. Dal Moro F, Aiello L, Pavarin P, Zattoni F. Ultrasound-guided transversus abdominis plane block (US-TAPb) for robot-assisted radical prostatectomy: a novel '4-point' technique-results of a prospective, randomized study. J Robot Surg. 2019;13(1):147-51.

9. Sun N, Wang S, Ma P, Liu S, Shao A, Xiong L. Postoperative analgesia by a transversus abdominis plane block using different concentrations of ropivacaine for abdominal surgery: a meta-analysis. Clin J Pain. 2017;33(9): 853-63.

10. Ghisi D, Fanelli A, Vianello F, Gardini M, Mensi G, La Colla L, Danelli G. Transversus abdominis plane block for postoperative analgesia in patients undergoing total laparoscopic hysterectomy: a randomized, controlled, observer-blinded trial. Anesth Analg. 2016;123(2):488-92.

11. Yuan Q, Cui X, Fei $Y, X u$ Z, Huang Y. Transmuscular quadratus lumborum block versus thoracic paravertebral block for acute pain and quality of recovery after laparoscopic renal surgery: study protocol for a randomized controlled trial. Trials. 2019;20(1):276.

12. Bjelland TW, Yates TGR, Fagerland MW, Froyen JK, Lysebraten KR, Spreng UJ. Quadratus lumborum block for postoperative analgesia after full abdominoplasty: a randomized controlled trial. Scand J Pain. 2019; 19(4):671-8

13. Bak H, Bang S, Yoo S, Kim S, Lee SY. Continuous quadratus lumborum block as part of multimodal analgesia after total hip arthroplasty: a case report. Korean J Anesthesiol. 2020;73(2):158-62.

14. Dhanjal S, Tonder S. Quadratus Lumborum block. In: StatPearls. Edn. Treasure Island (FL): StatPearls Publishing StatPearls Publishing LLC; 2019.

15. Kumar GD, Gnanasekar N, Kurhekar P, Prasad TK. A comparative study of transversus abdominis plane block versus quadratus lumborum block for postoperative analgesia following lower abdominal surgeries: a prospective double-blinded study. Anesth Essays Res. 2018;12(4):919-23.

16. Baytar C, Yilmaz C, Karasu D, Topal S. Comparison of ultrasound-guided subcostal transversus abdominis plane block and quadratus lumborum block in laparoscopic cholecystectomy: a prospective, randomized, controlled clinical ptudy. Pain Res Manag. 2019;2019:2815301.

17. Blanco R, Ansari T, Riad W, Shetty N. Quadratus lumborum block versus transversus abdominis plane block for postoperative pain after cesarean delivery: a randomized controlled trial. Reg Anesth Pain Med. 2016:41(6): 757-62.

18. Yousef NK. Quadratus lumborum block versus transversus abdominis plane block in patients undergoing total abdominal hysterectomy: a randomized prospective controlled trial. Anesth Essays Res. 2018;12(3):742-7.

19. Verma K, Malawat A, Jethava D, Jethava DD. Comparison of transversus abdominis plane block and quadratus lumborum block for post-caesarean section analgesia: a randomised clinical trial. Indian J Anaesth. 2019;63(10): $820-6$.

20. Ipek CB, Kara D, Yilmaz S, Yesiltas S, Esen A, Dooply S, Karaaslan K, Turkoz A. Comparison of ultrasound-guided transversus abdominis plane block, quadratus lumborum block, and caudal epidural block for perioperative analgesia in pediatric lower abdominal surgery. Turk J Med Sci. 2019;49(5): 1395-402.

21. Shan T, Bao HG. Efficiency of ultrasound-guided quadratus lumborum block for postoperative analgesia in puerperants underwent cesarean section. Jiangsu Med J. 2019;45(7):704-6.

22. Zheng W: Application of quaratus lumborum block versus transversus abdominis plane block on enhanced recovery after laparoscopic radical resection of colorectal cancer. Master. Nanchang University; 2019.

23. Ma CZ, Chen QY, Lin ZX, Zhang CC, Zhang Z. Effect of ultrasound-guided quadratus lumborum block for peritoneal dialysis catheter placement. J Clin Anesthesiol. 2019;35(10):961-4 
24. Fu K, Wei JY, Zhou FF, Hu QH. Comparison for the analgesic effect after inguinal herniorrhaphy in the elderly. Jiangxi Med J. 2019;54(5):551-3.

25. Han B, Wang B, He AP. Comparison of ultrasound-guided quadratus lumborum block and transversus abdominis plane block combined with patient controlled intravenous analgesia with sufentanil on post-operation analgesia after appendectomy. J Clin Anesthesiol. 2017:33(10):984-6.

26. Ye P, Lin YL, Liu YJ, Yu ZG. Comparison of analgesia effects between ultrasound-guided quadratus lumborum block and transversus abdominis plane block with assistance of patient controlled intravenous analgesia after laparoscopic cholecystectomy. J Trauma Emerg. 2019;7(2):93-7.

27. Yang ZP, Zhao WB. Effects of ultrasound-guided quadrate lumbar block and transverse abdominal block on postoperative analgesia of gynecological tumors. Sichuan Med J. 2019;40(6):566-70.

28. Zhu J, Ma JL, Gao YP. Effect of low back quadratus block and transverse abdominis block on postoperative analgesia in elderly patients undergoing radical gastrectomy. Guizhou Med J. 2019;43(9):1368-71.

29. Li N, Yue XQ. Analgesia effect study of ultrasound-guided lumbar quadratus block after laparoscopic myomectomy. Smart Healthcare. 2019;5(9):102-5.

30. Yang YP, Sun ZP, Xu JJ. Comparison of analgesic effect of dexmedetomidine combined with different nerve block pathways after cesarean section. Zhejiang Med J. 2019;21(9):1275-6.

31. Xia ZY, Bu HL, Wang ZF, Wang ZY, Zhang W. Efficiency of ultrasoundguided quadratus lumborum block for analgesia after laparoscopic cholecystectomy. Clin J Anesthesiol. 2018;38(8):950-2.

32. Ren BL, Feng AM, Qiao YS, Wang JW, Lu XH. Comparison of the analegesic effect between quadratus lumborum block and transversus abdominis plane block in laparoscopic operation. J Xinxiang Med Univ. 2018;35(8):719-21.

33. Zhu MH, Tang Y, Xu Q, Qin Q. Chen Y: quadratus lumborum block versus transversus abdominis plane block for analgesia after total abdominal hysterectomy. Int J Anesth Resus. 2018;39(8):741-5.

34. He WQ, Li YS, Zhang XH, Yi B, Lu KZ. Comparison of quadratus lumborum block and transversus abdominis plane block for postoperative analgesia in elderly patients undergoing abdominal surgery. Clin J Anesthesiol. 2018; 38(1):40-3.

35. Li G, Mamat R, Gai DX. Postoperative analgesia efficacy of quadratus lumborum block versus transversus abdominis plane block in patients undergoing caesarean section. Int J Anesth Resus. 2018;39(4):338-40.

36. White PF, Kehlet $H$. Improving pain management: are we jumping from the frying pan into the fire? Anesth Analg. 2007;105(1):10-2.

37. Mahama F, Ninnoni JPK. Assessment and management of postoperative pain among nurses at a resource-constraint teaching hospital in Ghana. Nurs Res Pract. 2019;2019:9091467.

38. Baeriswyl M, Zeiter F, Piubellini D, Kirkham KR, Albrecht E. The analgesic efficacy of transverse abdominis plane block versus epidural analgesia: a systematic review with meta-analysis. Medicine. 2018;97(26):e11261.

39. Soltani Mohammadi S, Dabir A, Shoeibi G: Efficacy of transversus abdominis plane block for acute postoperative pain relief in kidney recipients: a double-blinded clinical trial. Pain Med (Malden, Mass) 2014, 15(3):460-464.

40. Baker BW, Villadiego LG, Lake YN, Amin Y, Timmins AE, Swaim LS, Ashton DW. Transversus abdominis plane block with liposomal bupivacaine for pain control after cesarean delivery: a retrospective chart review. J Pain Res. 2018; 11:3109-16.

41. Jin Y, Li Y, Zhu S, Zhu G, Yu M. Comparison of ultrasound-guided iliohypogastric/ilioinguinal nerve block and transversus abdominis plane block for analgesia after cesarean section: a retrospective propensity match study. Exp Ther Med. 2019;18(1):289-95.

42. Kargar R, Minas V, Gorgin-Karaji A, Shadjoo K, Padmehr R, Mohazzab A Enzevaei A, Samimi-Sadeh S, Kamali K, Khazali S. Transversus abdominis plane block under laparoscopic guide versus port-site local anaesthetic infiltration in laparoscopic excision of endometriosis: a double-blind randomised placebo-controlled trial. BJOG. 2019;126(5):647-54.

43. Murouchi T, Iwasaki S, Yamakage M. Quadratus lumborum block: analgesic effects and chronological ropivacaine concentrations after laparoscopic surgery. Reg Anesth Pain Med. 2016;41(2):146-50.

44. Salama ER. Ultrasound-guided bilateral quadratus lumborum block vs. intrathecal morphine for postoperative analgesia after cesarean section: a randomised controlled trial. Korean J Anesthesiol. 2020;73(2):121-8.

45. Zhu Q, Li L, Yang Z, Shen J, Zhu R, Wen Y, Cai W, Liu L. Ultrasound guided continuous Quadratus Lumborum block hastened recovery in patients undergoing open liver resection: a randomized controlled, open-label trial. BMC Anesthesiol. 2019;19(1):23.
46. Ueshima $\mathrm{H}$, Hiroshi $\mathrm{O}$. Intermittent bilateral anterior sub-costal quadratus lumborum block for effective analgesia in lower abdominal surgery. J Clin Anesth. 2017;43:65.

47. Akerman $\mathrm{M}$, Pejcic $\mathrm{N}$, Velickovic I. A review of the quadratus lumborum block and ERAS. Front Med (Lausanne). 2018;5:44.

48. Putzu M, Gambaretti E, Rizzo F, Latronico N. Postoperative analgesia for laparotomic surgery provided by bilateral single-shot quadratus lumborum block. Minerva Anestesiol. 2018;84(10):1231-2.

49. Hussein MM. Ultrasound-guided quadratus lumborum block in pediatrics: trans-muscular versus intra-muscular approach. J Anesth. 2018;32(6):850-5.

50. Mieszkowski MM, Mayzner-Zawadzka E, Tuyakov B, Mieszkowska M, Zukowski M, Wasniewski T, Onichimowski D. Evaluation of the effectiveness of the quadratus lumborum block type I using ropivacaine in postoperative analgesia after a cesarean section - a controlled clinical study. Ginekol Pol. 2018;89(2):89-96.

51. Zhu M, Qi Y, He H, Lou J, Pei Q, Mei Y. Analgesic effect of the ultrasoundguided subcostal approach to transmuscular quadratus lumborum block in patients undergoing laparoscopic nephrectomy: a randomized controlled trial. BMC Anesthesiol. 2019;19(1):154

52. Young D. Policymakers, experts review evidence-based medicine. Am J Health Syst Pharm. 2005;62(4):342-3.

\section{Publisher's Note}

Springer Nature remains neutral with regard to jurisdictional claims in published maps and institutional affiliations.
Ready to submit your research? Choose BMC and benefit from:

- fast, convenient online submission

- thorough peer review by experienced researchers in your field

- rapid publication on acceptance

- support for research data, including large and complex data types

- gold Open Access which fosters wider collaboration and increased citations

- maximum visibility for your research: over $100 \mathrm{M}$ website views per year

At $\mathrm{BMC}$, research is always in progress.

Learn more biomedcentral.com/submissions 